\title{
Study on the Development of Cultural Tourism in Harbin City
}

\author{
SHI Changbo a, ${ }^{,}$, Xu Yanhong ${ }^{b}$ \\ School of Tourism and Cuisine, Harbin University of Commerce, Harbin, China \\ aemail: shicb777@sina.com, b jianada123@hotmail.com \\ ${ }^{*}$ Corresponding author
}

Keywords: cultural tourism, creative tourism, cultural creativity, Harbin City

\begin{abstract}
As a core city, cultural creativity has created new opportunities for the development of cultural tourism in Harbin City. There are some problems for cultural tourism in Harbin City, such as insufficient depth of tourism market development, incomplete development of tourist resources, and inadequate management. This paper analyzes the current situation of the development of cultural tourism in Harbin City, aiming at providing an effective strategy for the development of Harbin's cultural tourism industry.
\end{abstract}

\section{Introduction}

As a cultural activities, cultural tourism is to meet the diverse cultural experience needs of tourists' cultural consumption and cultural communication. It is the biggest difference between cultural tourism and other types of tourism, which cultural tourism has a tendency to pursue knowledge, information, education and other cultural factors. The fundamental driving force for cultural tourism sustainable development is the cultural creativity. Cultural tourism can meet the cultural needs of tourists and local residents, improve the cultural quality of local residents' life, and enhance the local cultural identity. Cultural tourism is a kind of social mechanism, which can coordinate and optimize the relationship between tourists and tourism destination through participation in interactive communication management. The development speed of cultural tourism is slow and the development level is low in Harbin City. Therefore, it is necessary to increase the intensity of cultural tourism development in Harbin City.

\section{Existing Problems of Cultural Tourism in Harbin Ctiy}

2.1 Lack of Creative Culture Connotation In the various scenic spots in Harbin Ctiy, the cultural atmosphere of tourist products is not strong, and lack of characteristic tourism products. The characteristics of cultural tourism resources lie in the history and culture. Due to historical reasons, the lack of cultural tourism products and commodity characteristics in Harbin Ctiy. There are many commodity to copy Russian products. The relevant departments should guide the tourism enterprise to transformate and upgrade, to implante Harbin' features in regional culture tourism products, native products, painting, painting, fashion, linen products, jewelry, health, leisure and other fashion products and services exhibition.

2.2 Lack of Innovation Design With the continuous expansion of the tourist market, tourist souvenirs become one of the essential consumption. There are generally lack of innovation in in the development of tourism products of Harbin scenic. At the same time there are low grades, rough packaging, lack of content, quantity, poor quality, difficult to find goods and so on. Therefore, creativity is particularly important in product development and design, so that Harbin tourism products can be more attractive. Therefore, it is a new way to promote the integration and innovation of culture and tourism industry, that encourage the design and development of fashionable tourism products with outstanding features, creativity and high market acceptance.

2.3 Lack of Overall Planning for Cultural Tourism Industry The overall planning is an important basis for the development of cultural tourism industry. In recent years, Harbin' cultural tourism 
industry has a growing trend, but the total culture of small scale, low share of contribution to economy, culture industry is still in the initial stage, has not yet formed the core competitiveness. Therefore, based on a comprehensive grasp of the current situation and development trend of cultural industry, some measures should be adopted, such as to propose guidelines of the long-term development of cultural tourism industry, implementation steps, methods and construction of key cultural projects. That can attract social capital investment, and build brand communication channels for the development of cultural tourism enterprises.

2.4 Lack of Cultural and Creative Talents Harbin high level of cultural and creative talent are scarce, especially in the project production, tourism product design, planning and operation management. The development of cultural tourism industry need fine professional, understand the economy and management leadership. However, due to personnel system obsolete, lack of self innovation and mechanism, and driven by economic interests, more and more people is unwilling to engage in low economic interests cultural work. At the same time, creativity is the seed of the cultural tourism industry, and it need the support of high-level talent resources with artistic creativity. This kind of "innovation" as a characteristic of high-level personnel resources is lack of cultural tourism industry in Harbin development. So talent shortage restrictes the development of Harbin cultural tourism industry.

2.5 Improper Exploitation of Cultural Tourism Resources Harbin is rich in tourism resources, but its brand is not strong, tourism products mining is not enough deep. Although there are many tourist routes in Harbin, but they stay on the surface. There is still a lack of good market prospects, construction standards, and attractions for tourists "cultural tourism" boutique. Tourists are not influenced by local culture and folk customs in the course of their travels. Harbin tourism industry should take the creative path of development, combine perfectly the tourist resources and creative spark, static tourism resources restructuring after the original re launch, in order to meet the needs of tourists, adapt to the development needs of the community, highlighting the charm of Harbin tourism industry.

\section{Development Countermeasures of Cultural Tourism in Harbin City}

3.1 Increase Infrastructure Construction Harbin should increase infrastructure construction, and require all localities and departments to take road network and other infrastructure in tourism development in the first place, with the overall layout of scenic spots construction and infrastructure construction, strengthen the planning and construction of roads into the tourism area, the fast passage between the smooth important scenic spots. Centring on the historical and cultural projects, Harbin should focus on mining the cultural connotation of a number of traditional historical and cultural blocks, such as the Central Street, Gogol Street, the Baroque Customs District. Harbin should strengthen infrastructure management of the Harbin Grand Theatre, Concert Halls and other cultural tourism, focus on investment to point a point, a pair of infrastructure for commercial development value, and build the new name card for historic district of creative tourism industry in Harbin city.

3.2 Pay Attention to the Cultivation of Tourist Talents There are two ways to provide protection for the development of cultural and creative tourism industry in harbin, one is can continue to introduce talents from other outstanding creative tourism area, the other is can cultivate creative talents localization as the focus. Firstly, Harbin should make preferential policy to introduce the creative talents, and organize large-scale creative exhibition, in order to attract innovative thinking and strong management ability of the professional cultural creative tourism talents to Harbin employment. Secondly, based on constantly introducing excellent foreign creative tourism talents, Harbin should more pay attention to cultivation of local cultural creative tourism talents. In the conditions allow universities and cultural and creative tourism related majors, cultivating new talents of cultural and creative tourism counterparts, which become the intellectual support for the tourism development of Harbin.

3.3 Promote the Transformation and Upgrading of the Cultural Industry Harbin should promote "tourism + creativity", cultural innovation and tourism products interaction, and cultivate new 
consumer hot spots. To comprehensively promote the development of tourism, culture, fashion industry integration, promote the development and utilization of old buildings and old landscape, enhance the cultural connotation of scenic spots, and create a model area of integration and development of tourism, culture and fashion. To explore the fashion highlights in various fields, through fashion week, fur Festival, model competition, Film Festival, animation week and other international fashion festival activities, to enhance the quality of Harbin city. To accelerate the integration of the development of tourism industry and the secondary industry, support Harbin Beer Factory, Harbin Pharmaceutical Group, and other large enterprises to develop industrial tourism projects, and encourage tourism enterprises to carry out product development industrial tourism. To support the development of new modes of tourism, shopping, tourism, real estate and other activities in the form of tourist shopping, through trains and tourist showings. To speed up the development of healthy old age tourism, expand the low altitude flying and self drive touring market, and support the local tourism enterprises to carry out online shopping, online travel, car rental and other new formats. 3.4 Accelerate "Summer City" Cultural City ConstructionThe development of cultural and creative tourism is conducive to expanding the credibility and influence of urban brands, and a variety of representative tourist souvenirs and tourist festivals are popular channels to enhance the brand influence and reputation of the city. In order to build tourism brand, through innovative practice, building tourism brand carrier and improving the creative market mechanism and other measures, Harbin City should take advantage of ice-snow, beer, wetland, leisure and music brand, to really realize deep fusion of ice-snow, wetland, music, culture, art and creative in "summer city". Continue to promote the integration of Harbin tourism festival activities, comprehensive integration and revitalize the city's summer tourism resources, to create financial, economic, cultural, sports, exhibition and other elements as one of the summer city brand "complex" -- "Charming Harbin Summer " fashion tourism culture activities, strengthen the tourism products of the cultural and creative content, and increase fashion factor. At the same time, pay attention to the key cooperation to strengthen publicity and APP and tourism operators, professional tourism website and other new media, through online and offline interaction, let Harbin have more affinity and charisma, to enhance the quality of life, fundamentally release personal creativity, promote common progress of human and society.

3.5 Design Professional Creative Travel Routes Harbin carry out tourism product development and promotion of cultural creative tourism through professional line design. At the same time, can also provide some cultural and creative tourism products to other tourist routes, let more guests recognize the cultural creative tourism products, which can expand the Harbin tourism through word-of-mouth. Harbin should enlarge the brand effect of Ice and Snow Festival, strengthen the creative idea, and promote the development of related tourism industry. Promote the traditional scenic ice technology, culture, management innovation, strengthen the integration of ice and snow both art and entertainment in the Ice and Snow World, Sunland Snow Expo, and Volga Manor, so as to form the core products and promote the overall development of winter tourism. At the same time, relying on the advantages of the ecological resources, sucn as wetlands, forests, hot springs, Harbin can introduce a number of distinctive characteristics and fashion elements of the summer tourism products, to expand the Harbin summer tourism influence.

3.6 Rich Cultural and Creative Tourism Products First, select the right entry point, highlighting the product hierarchy. Then, extract the theme, make the product and its related factors combination is more harmonious, so long as the theme more prominent and distinctive, more conducive to play a more deep and innovative products to meet various needs of tourists. Harbin cultural creative tourism industry brand through shaping the quality of tourism products and better service, to make it more professional and distinctive features, to form a strong attraction and competitiveness. Therefore, enhance the connotation of cultural and creative tourism products, rich tourism product content, both the depth of excavation and the key breakthrough, to develop the construction of a number of boutique tourism products, increase creative connotation, enhance the city's cultural and creative atmosphere, promote the creative tourism industry brilliant. 


\section{Acknowledgement}

This research was financially supported by Discipline project of Harbin University of Commerce: Study on the modern service industry to support Longjiang revitalization (Grant NO. hx2016001).

\section{References}

[1] B. McKercher, P. Ho, H. du Cros, Attributes of popular cultural attractions in Hong Kong, Annals of Tourism Research, vol. 23, pp. 393-407, 2004.

[2] C. J. Li, Qian cassia side path of ethnic cultural tourism with integrated developmen, Journal of Resources Development and Market, vol. 1, pp. 125-128, 2017.

[3] D. Chhabra, Staged Authenticity and Heritage Tourism, Annals of Tourism Research, vol. 30(3), pp. 702-719, 2003.

[4] D.L. Peng, Guizhou tun pu culture tourism resource development analysis, Journal of Central South Forestry University of Science and Technology (social science edition), vol. 1, pp. 69-72, 2017.

[5] L. K. Medina, Commoditizing culture tourism and Maya identity, Annals of Tourism Research, vol. 30(1), pp. 353-368, 2003.

[6] L.F. Bi, H.J. Xue, W. Wang, Dali, lijiang ethnic cultural tourism resources development path research, Journal of Shanxi Agricultural University (social science edition), vol. 6, pp. 56-62, 2017.

[7] M.B. Guo, The thinking and countermeasures of sichuan tourism industry cluster development, Journal of Enterprise Economy, vol. 11, pp. 120-123, 2012.

[8] S. Charters, J. Ali-Knight, Who is the wine tourist, Tourism Management, vol. 23, pp. 311-319, 2002. 